\title{
Research on the Implementation Path of Cultural Confidence Education Embedded in Professional Courses Under the Background of New Liberal Arts -Take "Chinese and Foreign Food Culture" as an Example
}

\author{
Ren Daxin ${ }^{1, *}$, Chen $\mathrm{Su}^{2}$ \\ ${ }^{1}$ College of Management, Shandong Technology and Business University, Yantai, Shandong, 264003, China \\ ${ }^{2} J u a n c h e n g$ First Middle School, Heze, Shandong 264000, China \\ *Corresponding author. Email: desren@126.com
}

\begin{abstract}
Cultural self-confidence education is an important part of university education. How to implement it under the background of new liberal arts has become an important work for university teachers. From the review of existing studies, it is found that the construction of professional courses will become one of the important means to cultivate college students' cultural self-confidence. Through in-depth interviews with teachers and students, it is found that the reform of teaching content, the improvement of teaching methods, the excavation of curriculum resources and the widening of communication channels between teachers and students can reasonably enhance students' cultural confidence. The study explores the process of embedding cultural selfconfidence in professional courses from a new perspective, which can not only cultivate students' cultural self-confidence, but also provide experience for similar courses.
\end{abstract}

Keywords: New liberal arts, professional courses, cultural confidence, implementation path, Chinese and

foreign food culture

\section{INTRODUCTION}

In 2019, 13 departments, including the Ministry of Education and the Ministry of Science and Technology, jointly launched the "Six Excellence and One Top-notch" Plan 2.0 to comprehensively promote the construction of "new engineering, new medical science, new agricultural science and new liberal arts". Although the concept of new liberal arts is constantly being interpreted and interpreted, the Declaration on the Construction of New Liberal Arts was released at the construction conference of new liberal arts held by Shandong University (Weihai) on November 3, 2020, making a comprehensive plan for the construction of new liberal arts. The conference put forward that "liberal arts education is the main battlefield, main position and main channel for cultivating self-confidence, pride and autonomy, generating influence, charisma and shaping power, and forming national cultural consciousness. The construction of new liberal arts is of great significance for promoting the innovative development of liberal arts education, constructing a new pattern of development of philosophy and social sciences centered on educating talents, accelerating the cultivation of liberal arts talents in the new era, and enhancing the soft power of national culture". Therefore, cultivating talents who know and love China and are worthy of national rejuvenation in the new era, cultivating social scientists in the new era, constructing the Chinese school of philosophy and social sciences, and creating Chinese culture that glorifies the food generation and the world will become the important goals of the construction of new liberal arts.

In this process, "cultivating self-confidence" has become one of the focal points in the construction of new liberal arts. However, how to cultivate self-confidence, what kind of self-confidence and how to cultivate self-confidence become the focus of the construction of new liberal arts. Admittedly, in college courses, a large number of public courses are one of the important ways to improve cultural confidence, but such courses are mostly offered for junior students, so for senior students, it is more important to appropriately embed cultural confidence education in professional courses. Therefore, this paper will take "Chinese and Foreign Food Culture" as an example, conduct in-depth interviews with teachers and students of this course, and discuss the implementation path of 
embedding cultural confidence education in professional courses.

\section{REVIEW OF RESEARCH RESULTS}

The so-called cultural confidence refers to the recognition and pride of a country and a nation on its own cultural value and the firm belief in its cultural vitality. In essence, it is the awakening of cultural value. College students are the future builders and successors of China, as well as an important force for inheriting and innovating Chinese culture. Their cultural value orientation and cultural behavior will influence the future cultural development of the Chinese nation. Therefore, the cultivation of young students' cultural confidence in colleges and universities is an important link to realize the cultural confidence of the Chinese nation. However, in real life, due to the impact of globalization and the rapid development of Chinese society, some college students have insufficient cultural confidence and lack of cultural confidence. Therefore, it is very important to cultivate the cultural confidence of college students at this stage.

\subsection{Research State in China}

In terms of academic research, by consulting the CNKI database, it is known that the research in this field is at the preliminary stage of exploration. The domestic research on cultural self-confidence was rare before 2002, and the number of research articles gradually increased after 2002 . The relevant research mainly focuses on following aspects. Regarding the research on the problems of cultural selfconfidence, most of this aspect is ideological and political education for college students. Wang tao (2020) [1] pointed out the main problems of college students' cultural self-confidence: insufficient national cultural cognition, low sense of identity; lack of advanced Chinese culture Attention, it is difficult to deal with cultural shock; blindly identify with foreign culture. Regarding the research on the reasons for the lack of cultural self-confidence, Wang ying (2020) [2] summarize the reasons for the lack of cultural self-confidence of college students. One is the impact of Western culture, the other is the lack of synchronization between cultural development and economic development, and the third is the lack of excellent traditional cultural education in schools. In addition, there are adverse effects of the network. Regarding the research on the cultivation path of cultural self-confidence, scholars have put forward many suggestions on the cultivation of cultural self-confidence. Wang Jingyun suggested that the cultural self-confidence of college students should be cultivated from three aspects: traditional culture, advanced mainstream culture and western culture. Liangxu (2020) [3] believe that the cultural self-confidence of college students should also be cultivated from the three aspects of college students' selfeducation, campus culture and network. Wei Hanbing
(2019) [4] proposed that traditional culture can be inherited and innovated from the three dimensions of content, practice, and innovation to enhance cultural selfconfidence.

Regarding cultural self-confidence and curriculum construction, most domestic scholars have expounded from the perspectives of university ideological and political courses and university basic courses (such as university Chinese and university English). For example, Lu Fengping (2018), Zhang Yanxia (2018), Liu Limin (2018), Lu Lei et al. (2017), Zhang Yahong (2017), etc. explained how to build the above-mentioned courses to achieve the purpose of improving the cultural confidence of college students. At the same time, many of the aforementioned authors also suggested that the traditional ideological and political course and university foundation courses, although teachers try to multi-angle, multi-level for students to improve self-confidence were tried, but with little success existence of the phenomenon. Most college students have a certain resistance to the traditional ideological and political courses and basic college courses, which is one of the main factors that have no obvious effect. Therefore, the construction of professional courses will become one of the important means to cultivate college students' cultural confidence.

\subsection{The Foreign Research Status}

"Cultural confidence" is a relatively new concept in China, so there are few relevant literatures. As for the term "cultural confidence", foreign scholars have not directly proposed or carried out a clear definition and research on it, and the research on college students' cultural confidence has not been involved. However, foreign scholars have conducted abundant studies on "culture" and "confidence" from different perspectives, different research methods and different directions, and these research results have certain reference value for our cognition of culture and confidence. For example, Clifford geertz (2014), huntington (1996), and Jonathan friedman $(2003,2017)$ all elaborated on the connotation, cultural identity, cultural communication, and cultural influence of culture from different levels.

On the research of "confidence", there are many empirical studies on the concept of confidence, the influencing factors of confidence, the methods to increase selfconfidence, and the difference of self-confidence. Clifford (1977) [5] pointed out in the hierarchy of needs theory that confidence is an emotional experience generated when self-esteem needs to be satisfied. Smitch (2012) [6] believed that "confidence is the self-evaluation made and kept by individuals, which indicates the extent to which individuals think themselves capable, important and valuable. Is an expression of approving or not approving attitude to oneself, appeared to oneself ability, identity, achievement and the value of faith ". Jackson (1984) pointed out that "confidence is not only a persistent personality tendency, but also a volatile self-evaluation state adjusted to the environment". Basch (1987) believes 
that "self-confidence is a person's feeling towards himself, and the key lies in the experience of ability".

Foreign scholars' views on "culture" and "confidence" provide reference for the research of China's cultural confidence. The mastery of the meaning of confidence can clarify what is the real confidence. Only the confidence of knowing, feeling, meaning and acting in four dimensions can be the real confidence and the cultural confidence in the most ideal state.

In addition, foreign countries focus on education, which is closer to the research direction of this paper, but the scope of traditional culture is broader than the connotation of cultural confidence in this paper. Although there is a certain degree of reference, but the difference is quite big. Therefore, there are many differences between the understanding of culture, confidence and curriculum construction in foreign countries and that in China. Although the views of culture and confidence can be used for reference, the implementation methods of how to integrate cultural confidence into curriculum construction are few and the enlightenment to China is also small.

\subsection{Domestic and Foreign Research Review}

To sum up, cultural confidence is a new concept proposed by China. Although many teachers in traditional ideological and political courses and university basic courses have made various attempts to improve college students' confidence from multiple perspectives and levels, they have little effect. It is one of the main factors that the effect is not obvious that most college students have some resistance to the traditional ideological and political courses and the basic courses. Therefore, the construction of specialized courses will become one of the important means to cultivate college students' cultural confidence. Foreign scholars in the "culture" and "confidence" in the research is relatively abundant, from different perspectives, different research methods, different directions on the research, the research results for cognitive culture, confidence has certain reference value, but how the cultural confidence into the course construction, the enlightenment to our country. Therefore, it has a positive effect to integrate cultural confidence into the tourism management specialized course "Chinese and Foreign Food Culture" and explore the cultivation of college students' cultural confidence.

\section{THE IMPLEMENTATION PATH OF CULTURAL CONFIDENCE EDUCATION EMBEDDED IN "CHINESE AND FOREIGN FOOD CULTURE"}

As the name suggests, professional courses are mainly based on professional education. There are some differences between professional courses and basic courses offered by universities in terms of curriculum objectives, teaching methods, curriculum setting and teaching grades.
It is worth exploring how to embed cultural selfconfidence in specific implementation path.

\subsection{Carefully Design the Course Content}

In the teaching process of "Chinese and Foreign Food Culture", specific modules are divided according to the teaching content, and the introduction of Chinese food culture, Chinese food culture, Chinese food folk customs, Chinese banquet culture, and the story of a leaf: Chinese tea culture, Chinese wine culture, chopsticks Culture, foreign food culture (food culture of major countries in Asia, America, and Africa), Sino-foreign food culture exchanges, topic one (food culture in the four classics), topic two (food culture in the Tang Dynasty) These teaching contents break the conventional chapter setting, summarize and summarize in a modular form, which is conducive to students' learning and acceptance. Reasonably embed the content of Chinese excellent food culture in the actual teaching content, such as embedding "the specific content of the food culture exchange between China and foreign countries" in the link of Chinese and foreign food exchanges, which arouses the resonance of students and provides knowledge support for them to build cultural confidence.

\subsection{Reasonable Use of Teaching Methods}

According to interviews with students, contemporary college students are relatively disgusted with traditional and rigid teaching methods, so the rational use of multiple teaching methods becomes crucial. In the course of teaching "Chinese and Foreign Food Culture", first of all, the PPT content was designed. PPT tries not to pile up large paragraphs of text. Key words use different colors to outline and type in the PPT. Use pictures and videos for dynamic display, which can reasonably attract students' attention. Second, the rational use of Rain Classroom. Rain Classroom has many functions, and the effect of interaction with students is obvious. In the link of embedded cultural self-confidence, it is carried out in the form of barrage, attracting students to think about the content of self-confidence in food culture, while teachers can flexibly grasp the dynamics of students, and can reasonably summarize and analyze the content of the barrage. Third, the use of group discussion and case analysis methods. Change the previous teacher's single lecture as the main, student-centered thinking and discussion of various issues, arouse students' interest in food culture from the heart, and then connect with the content of cultural confidence. Finally, teachers should be able to "let out and take back", make use of various teaching methods, and be able to summarize and summarize them, and guide students in their understanding of food culture through theoretical teaching. Cultivate students' cultural self-confidence. 


\subsection{Comprehensive Utilization of Various Curriculum Resources}

The various teaching platforms provided by MOOCS, Netease open courses, wisdom tree and other platforms of China University can provide a variety of in class resource platforms for Chinese and foreign food culture. Textbooks, library collections and CNKI can provide students with a variety of online or paper reading materials. The content of cultural self-confidence in these contents needs to be deeply explored by teachers and recommended to students for extracurricular learning. However, daily life, ancient novels, food culture and cultural self-confidence contained in local characteristics need teachers to find a suitable angle to dig in depth. For example, we set up a special topic "food culture in the four famous books", and combined with the teaching content, we summarized the raw materials, cooking methods, utensils, dish names, banquets, food etiquette and food theory, so as to guide students to establish cultural confidence, learn excellent culture identically, inherit and innovate, and encourage students to strive for the socialist cause.

\subsection{Broaden Communication Channels after Class}

Three-dimensional education requires not only the part of teaching knowledge in class, but also the communication with students after class is also on the agenda, especially in the cultivation of students' cultural confidence. Therefore, starting from the common food culture such as firewood, rice, oil, salt, sauce, vinegar and tea in daily life, build a three-dimensional education method through WeChat, QQ groups, and off-class interaction in Yu Class. After the theoretical knowledge taught in the class has been tested through practice in the classroom, students will be organized to discuss through WeChat groups and QQ groups after determining the relevant topics. Teachers can reasonably guide students to interact through group voting and group editing in the group. Methods After collecting students' ideas, flexible adjustments can be made in the classroom based on the content of the lessons to achieve the purpose of three-dimensional education. In addition, traditional after-school teacher-student seminars and email exchanges also need to be used flexibly.

\section{CONCLUSION}

University teachers undertake the sacred mission of teaching. They should be rooted in chinese tradition culture, full attention in the teaching and student management work life, civilizing, to better enhance the students' cultural confidence, further realize the outstanding traditional culture inheritance and innovation, and embedded in the professional course cultural confidence. In the specific implementation path, change the traditional teaching method, advocate the combination of humanistic spirit and scientific spirit curriculum; more discussion links and diversified education links should be added to break the traditional way of classroom teaching, encourage college students to think consciously, and promote the combination of theory and practice. Pay attention to the comprehensive investigation of students ability of social observation, analysis, understanding and thinking, so that students can not only analyze the society from the height of political theory, but also be able to correctly understand the society based on the reality and the problems around them. College teachers themselves should keep learning and innovating, keep pace with the times, break the shackles of old ideas, not only focus on students' knowledge education, but also care about students' adult education; make full use of local historical and cultural resources, guide the student to study the living condition of the traditional wisdom and human outstanding culture, make the college students really understand that the traditional culture is alive and valuable, thus really promoting the fusion of Chinese traditional culture and world culture communication progress and prosperity, in order to cultivate college students in human culture formed on the basis of the value of resource sharing, a high degree of cultural self-confidence.

\section{ACKNOWLEDGMENT}

This work was supported by Shandong Technology and Business University teaching reform project (Research on the Implementation Path of Cultural Confidence Education Embedded in Professional Courses under the Background of New Liberal Arts).

\section{REFERENCES}

[1] Wang tao, Research on Thanksgiving Education of post-95 college students from the perspective of cultural confidence, School and Ideological Education[J],2020,13: 78-80. (In Chinese)

[2] Wangying, Research on countermeasures to Cultivate College Students' Cultural Confidence, Theoretical observation [J], 2020, (6):137-139. (In Chinese)

[3] Liangxu, Research on ideological and Political Education of College Students from the perspective of cultural Confidence, Shaanxi youth [J], 2020, (4):155157. (In Chinese)

[4] Wei Hanbing, A Study on cultural Confidence of Contemporary College Students Theoretical observation [J], 2019, (10):121-123. (In Chinese)

[5] Clifford Geertz. The interpretation of cultures [M].New York: Basic Books, 1977.

[6] Smitch Clarks. Clash of Civilizations [M]. New York: Basic Books, 2012. 